EGGER, M. D., \& MILLER, N. E. Secondary reinforcement in rats as a function of information value and reliability of the stimulus. Joumal of Experimental Psy chology, $1962,64,97 \cdot 104$.

EGGER, M. D., MILLER, N. E. When is reward reinforcins? An experimental study of the information hypothesis. Joumal of Comparative \& Physiological Psychology, 1963, 56, 132-137.

ESTES, W. K., \& SKINNER, B. F. Some quantitative properties of anxiety. Joumal of Experimental Psychology, 1941, 29, 390-400.
MCCAUSLAND, D. F., MENZES, G. W., DEMPSEY, T. K., \& BIRKIMER, J. C. Response-contingent and non-contingent informative and redundant secondary reinforcers. Psychonomic Science, 1967, 8, 293-294.

SELIGMAN, M. E. P. CS redundancy and secondary punishment. Joumal of Experimental Psychology, 1966, 72, 546-5s0.

\section{NOTE}

1. This research was partially supported by NSF Grant No. 616-015 to the University of Florida.

\title{
Olfactory cues and spontaneous alternation behavior'
}

\author{
CHARLES L. RICHMAN, Wake Forest \\ University, Winston-Salem, N.C. 27109, \\ PAMELA JUELS, PHILIP PECKINPAUGH, \\ and ROBERT M. STUTZ, University of \\ Cincinnati, Cincinnati, Ohio 45221
}

Experiments were conducted to determine the effect of reward and drive on spontaneous alternation behavior (SAB) across trials. It was suggested that reinforcing severely food-deprived rats reduced $S A B$ across trials when direction was the sole relevant cue, but no reduction was found when odor cues were present. It was shown that $S A B$ decreases as a function of both days and trials of training.

In 1952, Montgomery suggested that spontaneous alternation behavior (SAB) was a result of an exploratory tendency. Using a cross-maze, Montgomery (1952) found that rats performed the same body-turn response in order to enter different goal arms Montgomery (1952) proposed that SAB was a special case of the rat's exploratory tendency, i.e., the novelty and hence the attractiveness of the goal entered on Trial 1 diminishes relative to the goal arm not visited.

Recently Douglas (1966) demonstrated that rats avoid their own odor trail. Since Montgomery (1952) used a procedure that did not control for odor trail, one might hypothesize that the Ss in his experiment were either avoiding their own odor and/or using odor as a discriminative cue for exploration. This study was designed to determine if, indeed, Montgomery's results might better be explained in terms of odor trail.

\section{EXPERIMENT 1 \\ Subjects}

The Ss were 4 experimentally naive hooded rats and 16 albino rats approximately 90 days old.

\section{Apparatus}

A cross-maze was constructed of unpainted white pine. All maze compartments were 2 in. wide and 4 in. high. The start and goal boxes were 8 in. long and the start and goal arms were 14 in. long. A plywood panel was used to block off one of the starting stems, at the choice point, thereby converting the cross into a $T$-maze. A wire mesh top covered the maze. The maze was placed on the floor of an $8 \times 8 \mathrm{ft}$ windowless room, illuminated by a $15-\mathrm{W}$ bulb suspended $3 \mathrm{ft}$ above the choice point. Procedure

Preliminary training consisted of 5 days of gentling followed by 2 days of six reinforced trials per day in a straight-alley maze (4 ft $x \quad 2$ in. $x \quad 4$ in.). During Preliminary Training Days $1-5$, Ss were maintained on a daily ad lib water schedule and 9-g Rockland lab chow. On Preliminary Training Days 6 and 7 and Experimental Days 14 , Ss were food-deprived except for the food consumed during training. Because of the Ss' apparent weakness they were given $4 \mathrm{~g}$ of lab chow, in their home cages, during Experimental Days 5 through 7.

Five Ss were randomly assigned to four groups; each group contained one hooded and four albino rats. The experiment consisted of a 2 by 2 design with two types of trial order and two odor trail conditions. The first letter (S or $\mathrm{C}$ ) refers to the trial starting stem order (successive or counterbalance) and the second ( $\mathrm{P}$ or $\mathrm{A}$ ) refers to the presence or absence of S's own odor trail. Groups S-P and S-A day's run began from one start stem direction [e.g., $(\mathrm{N})]$ for six successive trials then from the opposite start stem direction the next day [e.g., (S)] Groups $C \cdot P$ and $C$-A starting stem was varied within a day's run [e.g., (S), (N), (N), (S), $(\mathrm{S}),(\mathrm{N})]$. Odor trail presence or absence was manipulated in the following manner: Clean heavy brown paper inserts, covering the floor and walls of the goal arms, were used on Trial 1 each day. During each ITI for Group $P$, clean brown paper was inserted in the goal arm not visited so that there was always a "fresh" odor-trail goal arm and "clean" one. The brown paper inserts were changed in both arms at the end of each trial for Group A.

For 7 days each $\mathrm{S}$ was given six trials a day, thereby providing an opportunity for 35 goal-arm and/or odor-trail alternation responses. Animals received about 300-mg lab chow for entering either goal arm. The ITI ranged from 5 to $10 \mathrm{sec}$. A wooden block between the choice point and the goal arms prevented retracing.

Results

SAB was evaluated using a $\chi^{2}$ test comparing the observed distribution of alternation and nonalternation responses with a distribution based upon chance expectancies. $A \chi^{2}$ test was used for each of the four groups, the tests revealed that Groups S-P and C-P demonstrated SAB (79\% and $72 \%$ alternations with $\chi^{2}=19.68$, $\mathrm{df}=1, \mathrm{p}<.01$ and $\chi^{2}=9.94, \mathrm{df}=1$, $\mathrm{p}<.01$, respectively), but Groups $\mathrm{S}-\mathrm{A}$ and C-A did not demonstrate SAB ( $46 \%$ and $44 \%$ alternations with $\chi^{2}=.64, \mathrm{df}=1, \mathrm{p}>.10$ and $\chi^{2}=1.26$, $\mathrm{df}=1, \mathrm{p}>.10$, respectively). A t test comparing the number of goal-arm alternation responses between the successive and counterbalance trial order procedures ( $\mathrm{S}$ and $\mathrm{C}$ ) was statistically nonsignificant $(p>.05)$.

Discussion

Experiment 1 suggested that Montgomery's (1952) SAB finding was probably due to the rats' utilizing their own odor trails. The present study supported Douglas' (1966) demonstration that rats avoid their own odor trail at a higher-thanchance rate. However, Douglas (1966) also found that rats showed SAB to direction, e.g., east (E) and west (W), when no other cues were present. Thus, the control groups (Groups S-A and C-A) in this experiment should have demonstrated an above-chance rate of alternation behavior to the direction cue; these groups were in fact slightly below chance.

\section{EXPERIMENT 2}

In Experiment 1, Ss that were presented with direction as the sole cue failed to demonstrate SAB although Douglas (1966) found that Ss showed $\mathrm{SAB}$ to direction at a rate of about $63.5 \%$. The purpose of 
Experiment 2 was to identify the variable or variables that contributed to this variant finding. There were at least three factors that differed between Experiment 1 and Douglas' $(19(0)$ study: (1) In our experiment Ss were maintained on a fooddeprivation schedule, while Douglas' Ss were satiated: (2) Rats were reinforced in the former but not in the latter study; and (3) Experiment 1 consisted of six trials per day for 7 days whereas Douglas (1966) employed a two-trial per day procedure. Subjects

The Ss were 24 100-day-old experimentally naive albino rats.

\section{Apparatus}

The apparatus used in Experiment 1 was employed in this study.

Procedure

The preliminary training procedure was the same as in Experiment 1, except that all Ss were maintained on $9 \cdot \mathrm{g}$ lab chow per day throughout preliminary training. The design consisted of a 2 by 2 factorial with two levels of reward, 0 or $250 \mathrm{mg}$ of lab chow, and two levels of food deprivation, 0 or $23 \mathrm{~h}$. The first number designates reward magnitude $(0$ or 250 ) and the second the number of hours of food deprivation ( 0 or 23 ). The four groups were Groups $0-0,0-23,250-0$, and 250-23.

Subjects were run six trials per day for 7 days. Although the ITI was maintained at $10 \mathrm{sec}$; nonreinforced and satiated Ss traversed the maze more slowly than reinforced and satiated animals. This decrement in running speed was assumed unimportant in determining $\mathrm{SAB}$ since Gross, Black, \& Chorover (1968) recently demonstrated that ITIs ranging from 0 to $15 \mathrm{~min}$ had noeffect on SAB.

All 24 Ss followed the same start stem randomization order for the 42 experimental trials; a Fellows (1967) randomization series was employed for this purpose. Paper floor lining in both goal arms was replaced with clean sheets during the ITI. Reinforced animals were given $250 \mathrm{mg}$ of lab chow for either goal arm entry and $20 \mathrm{sec}$ to consume the food. 2 Food-deprived $S$ s were $23-\mathrm{h}$ food-deprived, and the satiated rats were given continual free access to food.

Results

The 24 Sscombined in one chi square test did not demonstrate $\mathrm{SAB}$ over the seven experimental days $\left(\mathrm{SAB}-56 \% ; \chi^{2}=1.44\right.$, $\mathrm{df}=1, \mathrm{p}>.05)$. However, individual $\chi^{2}$ tests revealed statistically significant $S A B$ for the reinforced $S s$ (SAB for Group $250.0=61 \%$ and Group $250-23=60 \% ; \chi^{2}=4.84, \mathrm{df}=1, \mathrm{p}<.05$ and $\chi^{2}=4.00, d f=1, p<.05$, respectively) and a lack of $S A B$ for the nonreinforced $S$ s (SAB lor Group $0.0=51 \%$ and Group 0.23=53\%: $\chi^{2}=.104 . \quad d f=1$. $\mathrm{p}>05$ respectively). An malysis of variance was performed on the group alternation scores across the 7 days; the reinforcement and trials main effects were statistically significant $(\mathrm{F}=5.33, \mathrm{df}=1 / 20$, $p<.05$ and $F=5.94, d f=6 / 120, p<.001$, respectively). Therefore, reinforced Ss alternated to direction cues at a higher rate than nonreinforced ones and $\mathrm{SAB}$ dissipated over days. A matched t test was performed on the total number of alternation responses for the 1st vs the 7 th experimental day $(t=3.83, \mathrm{df}=23, \mathrm{p}<.005)$; the former showed a greater number of alternation responses than the latter. A $\chi^{2}$ test revealed that the alternation rate on the 1 st day was above chance $\left(\mathrm{SAB}=68 \% ; \chi^{2}=12.96\right.$, df $=1, p<.001$ ) but on the 7 th day at chance level $\left(\mathrm{SAB}=49 \% ; \chi^{2}=.04, \mathrm{df}=1\right.$, $p>$.05).

Since SAB was found to decrease over days one may also speculate that alternation decreases over trials within a daily session. There were five possible alternation opportunities per animal each day. Combining all first alternation opportunities (FAO) for the 7 days and all last alternation opportunities (LAO) provided a means of assessing the probability of $S A B$ as a function of trials per day. A matched t test showed that during FAO there were significantly more alternations than during LAO $(\mathrm{t}=1.91$, df $=23$. $\mathrm{p}<.05)$; $\mathrm{SAB}$ was above chance level for the FAO scores $\left(\mathrm{SAB}=65 \% ; \chi^{2}=9.00, \mathrm{df}=1\right.$, $\mathrm{p}<.01)$ but not for the LAO data $\left(\mathrm{SAB}=57 \% ; \chi^{2}=1.96, \mathrm{df}=1, \mathrm{p}>.05\right)$.

To assess direction as a cue for $\mathrm{SAB}$ Douglas (1966) used two mazes placed in opposite directions in the same room and found that rats alternated at a rate of about $63.5 \%$. Douglas' Ss were satiated, nonreinforced, and run in only two sessions. The present experiment Group 0-0 FAO alternation scores are most analogous to Douglas' data. The percentage of alternation responses for the Group 0-0 FAO scores was $66.7\left(\chi^{2}=10.20, d f=1, p<.01\right)$.

\section{DISCUSSION}

The results of Experiment 2 showed that practice trials had a negative effect on albino rats' $\mathrm{SAB}$ when the sole cue present was direction. This demonstration was consistent with Spear, Hill, \& O'Sullivan's (1963) findings with albino rats. It was also shown that moderate amounts of reinforcement facilitated $\mathrm{SAB}$, a finding supported by Walker (1956).

In 1955 Bruner, Matter, \& Papaneck proposed that drive conditions may influence cue utilization, i.e., Ss under varying drive levels attend to specific cues at different probability levels. The results of Experiments 1 and 2 support th is hypotiesis when applied to $S A B$. In a post hoc inalysis of the results of Experim nut 1 and 2 a ( by Motivation interaction in suggested. In Experiment 1. severely ford-deprived, rein- furced Ss were presented with direction as the sole relevant cue and failed to maintain SAB above chance levels, yet under low or moderate deprivation states, in Experiment 2, reinforced Ss demonstrated SAB. This finding, at least for direction cues, is consistent with Dember \& Fowler's (1958) "empirical generalization" that severe deprivation conditions have a negative effect on SAB. However, severe drive conditions may have a position effect on $\mathrm{SAB}$ when odor trail cues are present. For example, Douglas (1966) found that satiated rats showed SAB to odor trail cues at a $65.6 \%$ level while our study's severely deprived Ss' SAB was about $10 \%$ higher ( $\bar{X}$ Groups S-P and $C \cdot P=75.5 \%$ alternations) after repeated trials. Accepting this comparison with caution, one may postulate that under severe drive conditions odor trail outweighs the importance of directional cues with the converse being true under low-to-moderate drive conditions. Intuitively, one might suspect that olfactory stimuli, because of their association with food, should be a predominant cue during severe drive states.

In both Experiments 1 and 2 it was shown that practiced Ss did not demonstrate $S A B$ to directional cues across trials and days. However, SAB was found in Experiment 2 when FAO scores were analyzed. These results restrict Douglas' (1966) findings of SAB due to direction cues to cases where limited practice is allowed.

\section{REFERFNCES}

BRUNER, J. S., MATTER, J., \& PAPANECK, M. L. Breadth of karning as a function of drive level and mechanization. Psychological Review, 1955, 62, 1-10.

DEMBER, W. H., \& FOWLER, H. Spontancous alternation behavior. Psychological Bulletin, $1958,55,412-428$.

DOUGLAS, R. J. Cues for spontaneous alternation. Journal of Comparative \& Physiological Psychology, 1966, 62, 171-183.

FEL LOWS, B. J. Chance stimulus sequence for discrimination tasks. Psychological Bulletin, 1967.67, 87-92.

GROSS, C.G., BI.AC K. P., \& CHOROVIE, S. L. Hippocampal lesions: leffects on memory in rats. Psychonomic Science, 1968. 12, 165-166.

MONTGOMI:RY, K.C. Exploration behavior and its relation to spontaneous alternation in a series of maze exposures. Joumal of Comparative \& Physiological Psychology. 1952, 45. 50-57.

SPIAR, N. I., HILL, W. I., \& O'SULLIVAN, D J. Spontaneous alternation with and without reward in hooded and albino rats. Psychological Reports, $1963.12 .441-442$.

WALKI R, I. L. The duration and course of reaction decrement and the influence of reward. Joumal of Comparative at Physiological Psy chology, 1956. 49, 167-176. NoTIS

1. The authors "ish to thank Mr. (icorge l dwards for his assistance in conducting 1 y periment 2 .

2. Although recris were not kept. it was observed that satiated reinforced animal reiroup

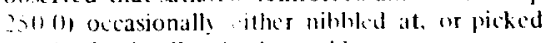
up. the food pollew in the rablar. 